\title{
Single Beat J-T Peak Interval
}

National Cancer Institute

\section{Source}

National Cancer Institute. Single Beat J-T Peak Interval. NCI Thesaurus. Code C117768.

An electrocardiographic interval measured from the J point to the peak of the T wave of a single beat utilizing one or more leads. (CDISC) 